\title{
Aristocratic Women and the Literary Nation, 1832-1867
}

\section{Claude Fierobe}

\section{OpenEdition}

1 Journals

\section{Édition électronique}

URL : http://journals.openedition.org/etudesirlandaises/1887

DOI : 10.4000/etudesirlandaises. 1887

ISSN : 2259-8863

\section{Éditeur}

Presses universitaires de Caen

\section{Édition imprimée}

Date de publication : 30 juin 2010

Pagination : 173-174

ISSN : 0183-973X

\section{Référence électronique}

Claude Fierobe, "Aristocratic Women and the Literary Nation, 1832-1867 », Études irlandaises [En ligne], 35-1 | 2010, mis en ligne le 30 septembre 2010, consulté le 21 septembre 2020. URL : http:// journals.openedition.org/etudesirlandaises/1887; DOI : https://doi.org/10.4000/etudesirlandaises. 1887

Ce document a été généré automatiquement le 21 septembre 2020.

\section{(c) (i) 8 ()}

Études irlandaises est mise à disposition selon les termes de la Licence Creative Commons Attribution - Pas d'Utilisation Commerciale - Partage dans les Mêmes Conditions 4.0 International. 


\title{
Aristocratic Women and the Literary Nation, 1832-1867
}

\author{
Claude Fierobe
}

\section{RÉFÉRENCE}

Muireann Ó Cinnéide, Aristocratic Women and the Literary Nation, 1832-1867, Palgrave Studies in Nineteenth-Century Writing and Culture, Houndmills, Basingstoke, PalgraveMacmillan, 2008, VII+241 p., ISBN 978-0-230-54670-7

1 L'auteure part d'un constat très simple : " Aristocratic women in the Victorian period experienced a particular combination of gendered exclusion and class privilege in their lives and writing. " De là cette étude qui s'inscrit entre les deux grandes réformes électorales de 1832 et 1867 , et où «the literary nation " veut dire à la fois la représentation de la nation dans la littérature, et la nation elle-même telle qu'elle est façonnée par la littérature. L'introduction précise en outre la méthode et le cadre théorique.

2 La première partie ("Class and Authorship") examine les rapports entre écriture féminine, pouvoir de représentation et pertinence universelle, et souligne les limites de l'exercice par les risque encourus, par exemple frivolité de la communication mondaine au détriment d'un contenu sérieux, politique. Plusieures question sont abordées: l'autobiographie, façonnée par l'origine sociale, a-t-elle une véritable visée culturelle? Y-a-t-il émergence d'un modèle générique? Quelle est la place de ces auteures sur le marché littéraire? Dans la deuxième partie ("Writing the Nation State") on voit que ce mode d'écriture permet d'intervenir dans les affaires de l'État, et le rôle joué par Rosina Bulwer Lytton et Caroline Norton, qui refusent d'être cantonnées dans le domaine domestique, pousse à une révision profonde du rôle de la femme dans la société. La politique parlementaire elle-même se trouve influencée par celles qui font entendre leur voix. Une brève incursion au delà de la période étudiée montre l'apparition de formes d'action féminine plus organisée et sans doute plus personnalisée. 
3 Ainsi, le grande mérite de ce livre est de montrer de façon érudite et méthodique que les femmes de l'aristocratie tentaient de se frayer un chemin entre inclusion et exclusion pour constituer une identité auctoriale bien réelle.

4 Aristocratic Women retiendra l'attention des irlandisants. Dans une Irlande 'unie' à la Grande-Bretagne depuis le début du siècle, sont évoquées des figures très différentes. D'aborde Marguerite Power, comtesse de Blessington, dont le parcours est emblématique : née dans le Comté de Tipperary, épouse du comte de Blessington en seconde noce, elle vit sur le continent, revient à Londres à la mort de son mari, écrit plusieurs 'silver fork novels' où elle égratigne la haute société et prétend que la fiction peut contribuer à réformer la société. Puis deux femmes dont M. O'Cinneide écrit fort justement : «Both were of Irish background and ambiguous social standing. » D'un côté Rosina Bulwer Lytton, née en Irlande en 1802, objet d'une pénétrante analyse ("Motherhood and madness"); de l'autre Caroline Norton (petite fille de Richard Brinsley Sheridan), qui milite pour le droit des femmes à garder leurs enfants et ne cesse d'écrire, prose et poésie, jusqu'à sa mort. Lady Morgan, quant à elle, doit son ascension sociale à ses succès littéraires et plaide en faveur d'une juste et authentique unification de l'Irlande et de la Grande-Bretagne.

5 Les notes (27 p.), la bibliographie (20 p.) et un excellent index complètent un ouvrage qui explore avec rigueur les concepts d'identité, de classe et de genre, dans le domaine féminin si complexe de l'interaction entre sphère publique et sphère privée. 